\title{
Infection, Causation and Indigenous Flora
}

\section{Reginald F. Baugh ${ }^{1 *}$ and Aaron D. Baugh ${ }^{2}$}

${ }^{1}$ Division of Otolaryngology, University of Toledo, USA

${ }^{2}$ University of Toledo School of Medicine, USA

Each unique microenvironment of the human body is colonized by indigenous flora generally believed to be present within a complex biofilm. The symbiosis that describes the relationship between endogenous flora and the host is not a static situation but a dynamic milieu capable of continuous change. As the microenvironment changes, the relative number and distribution of individual organisms change [1]. Everything from cigarette smoke [2] to the development of an oral cancer [3] have been shown to alter the composition of the indigenous flora on head and neck mucosa. Most relationships between organisms or between the host and the organism in the head and neck are either not known, poorly understood or both. At the heart of the problem is that we do not know the organisms present, much less the complex interrelationships between the microbes and their interactions with host defenses that lead to infection.

The Roman physician's Aulus Cornelius Celsus's description of the host response-rubor (redness), calor (fever), dolar (pain), and tumor (swelling)-has governed the decision process regarding the presence or absence of an infection for nearly two thousand years. The decision has been a dichotomous one based upon host response. The foundation of microbial disease causation and treatment: a specific association of an organism with a specific diseased state; agreement of microbiological, pathologic and clinical evidence; and growth of the microbe by culture was summarized by Koch [4] in what have been known as the Koch postulates. Later disciples added the requirement for re-isolation from an experimentally inoculated host. Isolation of the organism by culture techniques from the infection source was key and was the link to causation.

The preponderance of evidence now suggests that Koch's postulates as an underpinning of clinical microbiology is inadequate. At the heart of the issue are a relative few facts. Most organisms involved in infection do not grow in culture [5]. Outside laboratory conditions, most bacteria grow in biofilms rather than planktonically $[6,7]$. By contrast, culture techniques by design select for the growth of single organisms under planktonic conditions, suppress multiple of organisms and are oblivious to most biofilms and simply ignore possible interactions between bacteria. Biofilms impart both resistance to host immune defense mechanisms $[8,9]$ antibiotic treatment [10], and promote the development of resistant planktonic forms $[11,12]$. Even the antibiotic sensitivities of organisms grown planktonically and in biofilms may differ $[13,14]$.

Hence, our reliance on cultures may be suspect. An example will illustrate. Pseudomonas aeruginosa is widely viewed as the primary organism of the external ear canal. When molecular non-culture techniques were applied to the normal ear canal, 310 organisms and 7 fungi were identified, some for the first time [15]. Clinically, however, less than three organisms are routinely identified when cultures are obtained. The gap between what is reflected in routine clinical cultures and the sheer number and diversity of organisms identified by non-culture techniques makes the conclusions we so comfortably reach daily far less comfortable.

At the heart of the problem may be our dichotomous conceptual framework of infection. Traditionally, non-self agents (bacteria, viruses, fungi) "infect" the host (self). Charles A. Janeway's concepts [16] further articulated in the danger signal model offers clear advantages over the traditional view of infection. This theory posits control of innate immunity through two evolutionary conserved broad molecular patterns, pathogen-associated (PAMP's) and its counter-point, damageassociated molecular pathogens (DAMP's). Bacterial alarmins such as lipopolysaccharide (LPS) or bacterial DNA activates the former while high motility group box 1 (HMGB1), an endogenous alarmin works through the latter. Endogenous alarmins are typically intra-cellular structures rapidly released during necrosis or injury but sequestered in apoptosis and potentially actively secreted by immune cells.

Whereas the self/non-self model is unable to reconcile activation of the immune system by sterile injury or autoimmunity, the concept of danger signaling offers a clear rationale for both phenomenon. By its logic, pathogenic and endogenous cell components act as danger signals activating the innate immune system. Infection, then, is not a dichotomous event but a continuum based immune activation. The amount of immune activation reflects the degree of recognition by the body. The symbiosis that describes the relationship between endogenous flora and the host is not a static situation but a dynamic milieu capable of continuous change based upon the degree of immune recognition of the endogenous organisms and their own interaction with each other. Moreover, infection itself is no longer the focus of care, except where subordinate to immune activation, and pathology indicated by increased danger signals.

Although our understanding has not been complete, we have manipulated the resident nasopharynx micro flora and biofilms directly with favorable outcomes $[17,18]$. Even time honored surgical therapy of head and neck infectious conditions such as tonsillectomy, adenoidectomy, sinus surgery and tympanostomy tube placement may do nothing more than induce a change in local microflora. Recent studies of the nasopharyngeal flora following adenoidectomy provide evidence of the elimination of pathogenic bacteria from the nasopharynx following adenoidectomy [19]. These findings provide a rationale for the success of adenoidectomy in children with recurrent otitis media and as the initial surgical treatment of pediatric sinus disease. Tympanostomy tubes and modern surgical treatment of chronic sinusitis whether by sinuplasty or resection embraces the concept of "aeration" and may ultimate work through similar alteration of the microenvironment.

Resident flora are capable of continuous change as determined by selective pressures of the environmental milieu. On and within the human body, microbial cells outnumber human cells by as many as

*Corresponding author: Reginald F. Baugh, MD, Division Director, Otolaryngology, University of Toledo, 3000 Arlington Avenue, MS 1095, Toledo, $\mathrm{OH} 43614$, USA Tel: 419-383-6834; Fax: 419-383-3105; E-mail: reginald.baugh@utoledo.edu

Received December 12, 2011; Accepted January 16, 2012; Published January 21,2012

Citation: Baugh RF, Baugh AD (2012) Infection, Causation and Indigenous Flora. J Aller Ther 3:e104. doi:10.4172/2155-6121.1000e104

Copyright: @ 2012 Baugh RF, et al. This is an open-access article distributed unde the terms of the Creative Commons Attribution License, which permits unrestricted use, distribution, and reproduction in any medium, provided the original author and source are credited. 
10:1. Our use of antibiotics increases every year, enhancing selective pressures within the environment and fostering greater resistance. The wisdom of using ever more powerful broad spectrum antibiotics is questionable as gaps created by non-selective killing are always filled by some organism; at times by some that may not be just be undesirable but harmful. Our focus should be to re-establish microbial homeostasis between the resident microorganisms and the host.

Critical gaps in our understanding of the organisms and the interactions resulting in health and disease remain. A thorough understanding of the interacting of human cells and resident flora awaits development of complex models that better replicate symbiotic nature of interactions within our body. As our understanding of infectious diseases expands, the need to surgically manipulate head and neck microflora may be rendered unnecessary, radically changing our specialty.

\section{References}

1. Schauber J, Dorschner RA, Yamasaki K, Brouha B, Gallo RL (2006) Control of the innate epithelial antimicrobial response is cell-type specific and dependent on relevant microenvironmental stimuli. Immunology 118: 509-519.

2. Brook I, Gober AE (2007) Effect of smoking cessation on the microbial flora. Arch Otolaryngol Head Neck Surg 133: 135-138.

3. Nagy KN, Sonkodi I, Szoke I, Nagy E, Newman HN (1998) The microflora associated with human oral carcinomas. Oral Oncol 34: 304-308.

4. Koch R (1884) Die Aetiologie der Tuberkulose. Mitt Kaiser Gesundh 2: 1-88.

5. Geesey GG, Richardson WT, Yeomans HG, Irvin RT, Costerton JW (1977) Microscopic examination of natural sessile bacterial populations from an alpine stream. Can J Microbiol 23: 1733-1736.

6. Dees PM, Ghiorse WC (2001) Microbial diversity in hot synthetic compost as revealed by PCR-amplified rRNA sequences from cultivated isolates and extracted DNA. FEMS Microbiol Ecol 35: 207-216.

7. Lewis K (2007) Persister cells, dormancy and infectious disease. Nat Rev Microbiol 5: 48-56.

8. Buret A, Ward KH, Olson ME, Costerton JW (1991) An in vivo model to study the pathobiology of infectious biofilms on biomaterial surfaces. J Biomed Mater Res 25: 865-874

9. Gilbert P, Collier PJ, Brown MR (1990) Influence of growth rate on susceptibility to antimicrobial agents: biofilms, cell cycle, dormancy, and stringent response. Antimicrob Agents Chemother 34: 1865-1868.

10. Hoyle BD, Jass J, Costerton JW (1990) The biofilm glycocalyx as a resistance factor. J Antimicrob Chemother 26: 1-5.

11. Vaudaux $P$, Francois $P$, Berger-Bachi $B$, Lew DP (2001) In vivo emergence of subpopulations expressing teicoplanin or vancomycin resistance phenotypes in a glycopeptide-susceptible, methicillin-resistant strain of Staphylococcus aureus. J Antimicrob Chemother 47: 163-170.

12. Chen HY, Yuan M, Livermore DM (1995) Mechanisms of resistance to betalactam antibiotics amongst Pseudomonas aeruginosa isolates collected in the UK in 1993. J Med Microbiol 43: 300-309.

13. Hill D, Rose B, Pajkos A, Robinson M, Bye P, et al. (2005) Antibiotic susceptabilities of Pseudomonas aeruginosa isolates derived from patients with cystic fibrosis under aerobic, anaerobic, and biofilm conditions. J Clin Microbiol 43: 5085-5090.

14. Slinger R, Chan F, Ferris W, Yeung SW, St Denis M, et al. (2006) Multiple combination antibiotic susceptibility testing of nontypeable Haemophilus influenzae biofilms. Diagn Microbiol Infect Dis 56: 247-253.

15. Stroman DW, Roland PS, Dohar J, Burt W (2001) Microbiology of normal external auditory canal. Laryngoscope 111: 2054-2059.

16. Janeway CA (1989) Approaching the asymptote? Evolution and revolution in immunology. Cold Spring Harb Symp Quant Biol 54: 1-13.

17. Falck G, Grahn-Hakansson E, Holm SE, Roos K, Lagergren L (1999) Tolerance and efficacy of interfering alpha-streptococci in recurrence of streptococcal pharyngotonsillitis: a placebo-controlled study. Acta Otolaryngol 119: 944-948.

18. Tano K, Grahn Håkansson E, Holm SE, Hellstrom S (2002) A nasal spray with alpha-haemolytic streptococcie as long term prophylaxis against recurrent otitis media. Int J Pediatr Otorhinolaryngol 62: 17-23.

19. Le TM, Rovers MM, van Staaij BK, van den Akker EH, Hoes AW, et al. (2007) Alterations of the oropharyngeal microbial flora after adenotonsillectomy in children: a randomized controlled trial. Arch Otolaryngol Head Neck Surg 133 969-972. 